\title{
Association between early childhood caries and maternal caries status: A cross-section study in São Luís, Maranhão, Brazil
}

\author{
Pedrita Mara do Espírito Santo de Souza ${ }^{1}$, Mariana Almeida Mello Proença ${ }^{1}$, \\ Mayra Moura Franco ${ }^{1}$, Vandilson Pinheiro Rodrigues ${ }^{2}$, José Ferreira Costa ${ }^{1}$, \\ Elizabeth Lima Costa ${ }^{1}$
}

Correspondence: Dr. Vandilson Pinheiro Rodrigues Email: vandilson@hotmail.com

\author{
'Department of Dentistry, Federal University of \\ Maranhão, São Luís, Maranhão, Brazil, \\ 2Department of Morphology, University of Maranhão, \\ São Luís, Maranhão, Brazil
}

\section{ABSTRACT}

Objective: This study aims to evaluate the association between early childhood caries (ECC) and maternal caries status, and the maternal perception of ECC risk factors. Materials and Methods: A cross-sectional study was carried out with 77 mother-child pairs, the children ranging from 12 to 36 months of age and their mothers, who were seeking dental care at a health center in São Luís, Maranhão, Brazil. Data collection was conducted using a specific questionnaire for mothers. Oral clinical examination of the mother-child binomial to assess caries incidence, gingival bleeding (GB) and visible plaque was done. Home visits were performed in $10 \%$ of the sample in order to observe the environmental conditions, dietary habits and dental hygiene practices. Results: The findings showed that the caries prevalence in children was 22.5 times higher in the mother who had decayed tooth (prevalence ratio $[\mathrm{PR}]=22.5$, confidence interval $[\mathrm{CI}] 95 \%=3.2-156.6, P<0.001$ ). GB also was observed in 14 mothers and children, the PR in pair was $12.2(\mathrm{CI} 95 \%=1.6-88.9, P<0.001)$. The variables are related for the mother-child binomial in regression linear analysis. Conclusion: The maternal caries status was associated with ECC.

Key words: Dental caries, maternal behavior, preventive dentistry, risk factors

\section{INTRODUCTION}

The dental caries results of a localized demineralization in dental surfaces caused by metabolic events that occur in the dental plaque located in the affected area. ${ }^{[1]}$ Early childhood caries (ECC) is characterized by affecting several teeth, by occurring in areas considered of low risk and by showing rapid progression. ${ }^{[2]}$ Evidences suggest that maternal factors influence bacterial acquisition, ${ }^{[3]}$ thus the oral health behaviors, access to dental care, poor oral hygiene, and consumption of sugar feeding habits have been linked as risk factors for ECC. ${ }^{[4]}$

The understanding the development of caries as a multifactorial disease involves biological factors that act directly on the de-remineralization (biofilm, diet, saliva), ${ }^{[5]}$ as well as factors that modify or modulate the outcome (income, education level, and health status). ${ }^{[6]}$ Moreover, ECC affects the quality of life of children due to dental pain and subsequent tooth loss, resulting in difficulty in eating, speaking, sleeping and socializing, ${ }^{[7]}$ which can be avoided with early dental care.

The family environment also exerts great influence on the child, and parental attitudes can affect children's behavior, thus reflecting on oral health. ${ }^{[8]}$ The vertical transmission of cariogenic agents is supported by the fact that people with poor oral health tend to have parents with poor oral health, which can be explained by the interaction between genetic and

\footnotetext{
How to cite this article: de Souza Pd, Mello Proença MA, Franco MM, Rodrigues VP, Costa JF, Costa EL. Association between early childhood caries and maternal caries status: A cross-section study in São Luís, Maranhão, Brazil. Eur J Dent 2015;9:122-6. 
environmental exposures. ${ }^{[9,10]}$ This study aims to evaluate the association between ECC and maternal caries status, and the maternal perception of ECC risk factors.

\section{MATERIALS AND METHODS}

This study was approved by the Committee of Ethics in Research of the Federal University of Maranhão (UFMA), under registration No. 23115012534/2008-41. The mothers responsible for the children were informed of the study and signed a term of free and informed consent.

Seventy-seven children from 12 to 36 months of age and their mothers were selected from among those who sought medical/dental assistance at a health center located in São Luís, Maranhão, Brazil, in the period from August 2009 to July 2010.

To carry out a risk profile analysis, a clinical examination of the oral cavity was conducted in order to observe the conditions of the mucous membranes (if dry and/or opaque), the characteristics of carious lesions (soft or not) and the presence of white spots in areas of greater or lesser susceptibility to caries disease. The prevalence of dental caries was evaluated using the decayed, missing, and filled teeth indexes. The visible plaque index used to evaluate the amount of dental plaque or dental biofilm assigns values of 1.0 for a tooth with visible plaque and 0.0 for a tooth with no visible plaque. The gingival bleeding index was used to evaluate the periodontal condition, where the 0 score stands for the absence of GB and 1 for the presence of GB. All diagnostic steps were carried out in the Pediatric Health Center.

The mothers responded to a questionnaire containing 29 closed questions related to the study. After that, in order to provide additional ethnographic information, home visits were conducted with seven families to observe "in locu" the environmental conditions, dietary habits and dental hygiene practices of mothers and children. During the home visits, supervised tooth brushing activities were carried out on the mothers and their children, in order to clarify possible questions about how to perform oral hygiene in children.

The data were analyzed first in a mechanical form and later in electronic form. SPSS 17.0 (IBM SPSS Inc., Chicago, IL, USA) was used for the tabulation and analysis of the results. The Kolmogorov-Smirnov test was applied to verify the normal distribution of the sample. The Mann-Whitney test $(\mathrm{U})$ was used to evaluate the relationship between the variables in the mother-child binomial since the sample studied does not belong to a normal distribution. The linear regression test, by the backward method, was applied for verification of relationship among the variables studied. The level of significance adopted was $5 \%$.

\section{RESULTS}

Regarding the percentage distribution by socioeconomic status of mothers, the data show that, of the 77 mothers interviewed, 39 mothers $(50.6 \%)$ have high school education. The predominant household income ranged from 1 to 3 minimum wages (84.4\%), representing low socioeconomic status.

Of the 77 mothers interviewed, 58 mothers (75.3\%) said that their children have a habit of waking up during the night to breastfeed, 45 (58.4\%) breastfeed to sleep and $36(46.7 \%)$ use the bottle during the night. Of these 36 children, 14 (38.8\%) wake up once during the night to breastfeed and 14 (38.8\%) wake up twice. When it comes to adding sugar to the baby bottle, $47(61 \%)$ mothers responded that they do it [Table 1].

Table 2 shows the results of oral hygiene practices, guidance on oral health and oral habits: 43 mothers $(55.8 \%)$ said that oral hygiene should be started as soon as the baby is born, $34(44.2 \%)$ use toothbrush and toothpaste for the oral hygiene of their child, and 39 (50.7\%) do that twice a day. Of the 77 mothers interviewed, $55(71.4 \%)$ did not receive oral health guidance during pregnancy, 41 (53.2\%) do not know when to make the first visit to the dentist,

\begin{tabular}{lc}
$\begin{array}{l}\text { Table 1: Percentage distribution of the children's } \\
\text { eating habits }\end{array}$ & Frequency $\boldsymbol{n}$ (\%) \\
\hline Variables & $58(75.3)$ \\
\hline Wake up during the night to breastfeed & $19(24.7)$ \\
Yes & \\
No & $45(58.4)$ \\
Breastfeed to sleep & $32(41.6)$ \\
Yes & \\
No & $36(46.7)$ \\
Bottle during the night & $41(53.3)$ \\
Yes & \\
No & $14(38.8)$ \\
Frequency of bottle use & $14(38.8)$ \\
1 time & $8(22.4)$ \\
2 times & \\
3 times & $47(61.0)$ \\
Add sugar to the bottle & $30(39.0)$ \\
Yes & \\
No &
\end{tabular}


and 35 (45.4\%) received such information from their pediatrician. When asked about information and habits related to ECC, 14 mothers (18.2\%) said they had heard about the subject, 10 (13\%) knew how it is transmitted, 39 (50.6\%) tasted the baby food, $23(29.9 \%)$ blew on the food, and 11 (14.3\%) kissed the baby on the mouth.

Table 3 presents the oral conditions evaluated during the clinical examination. It shows that the caries prevalence in children was 22.5 times higher in the mother who had decayed tooth (prevalence ratio [PR] $=22.5$, confidence interval $[\mathrm{CI}] 95 \%=3.2-156.6$, $P<0.001)$. GB also was observed in 14 mothers and children, the PR in pair was 12.2 (CI95\% = 1.6-88.9, $P<0.001)$. On the other hand, 35 mothers and children did not present GB. Visible plaque present in 35 mothers and children simultaneously; and was absent, at the same time, in 26 mothers and children, the PR was $4.1($ CI95\% $=2.1-7.8, P<0.001)$.

The linear regression test showed that all $P$ values statistically significant, therefore, the variables are related for the mother-child binomial. However, from the beta coefficient onward, it can be concluded in all cases that the relationship among the variables in the sample studied was considered average [Table 4].

\section{DISCUSSION}

Tooth decay is a multifactorial disease that occurs due to the interaction of certain causal factors. The interrelation of cariogenic microbiota with the appropriate substrate, in a susceptible host, within a certain time, permeated by broad social, economic and cultural factors, influence the development and evolution of the disease. ${ }^{[11]}$

There is still no consensus in the literature regarding the importance of maternal schooling on the development of caries. Some authors claim that there is no relationship between these two variables. ${ }^{[12]}$

\begin{tabular}{|c|c|}
\hline Variables & $\begin{array}{c}\text { Frequency } \\
n(\%)\end{array}$ \\
\hline \multicolumn{2}{|l|}{ Start of the baby's oral hygiene } \\
\hline As soon as the baby is born & $43(55.8)$ \\
\hline When the teeth erupt & $20(40.2)$ \\
\hline Don't know & $14(18.2)$ \\
\hline \multicolumn{2}{|c|}{ What to use for the baby's hygiene } \\
\hline Not done & $12(15.6)$ \\
\hline Gauze/cloth with water & $31(40.2)$ \\
\hline Toothbrush with tooth paste & $34(44.2)$ \\
\hline \multicolumn{2}{|l|}{ Frequency of the baby's hygiene } \\
\hline 1 time & $11(14.3)$ \\
\hline 2 times & $39(50.7)$ \\
\hline More than 2 times & $27(35.0)$ \\
\hline \multicolumn{2}{|c|}{ Received dental guidance during pregnancy } \\
\hline Yes & $22(28.6)$ \\
\hline No & $55(71.4)$ \\
\hline \multicolumn{2}{|c|}{ When the first visit to the dentist should be made } \\
\hline Don't know & $41(53.2)$ \\
\hline Shortly after birth & $2(2.6)$ \\
\hline When the teeth appear & $34(44.2)$ \\
\hline \multicolumn{2}{|c|}{ Who supplied information about the baby's oral care } \\
\hline Never got information & $27(35.1)$ \\
\hline Dental students & $15(19.5)$ \\
\hline Pediatrician & $35(45.4)$ \\
\hline
\end{tabular}

\begin{tabular}{|c|c|c|c|c|}
\hline \multirow[t]{2}{*}{$\begin{array}{l}\text { Variables } \\
\text { in mother }\end{array}$} & \multicolumn{2}{|c|}{$\begin{array}{c}\text { Variables in child } \\
n(\%)\end{array}$} & \multirow[t]{2}{*}{ PR (Cl 95\%) } & \multirow[t]{2}{*}{$P$} \\
\hline & Yes & No & & \\
\hline \multicolumn{5}{|c|}{ Dental caries } \\
\hline Yes & $30(68.2)$ & $14(31.8)$ & $22.5(3.2-156.6)$ & $<0.001^{*}$ \\
\hline No & $1(3.0)$ & $32(97.0)$ & Reference & \\
\hline \multicolumn{5}{|l|}{ GB } \\
\hline Yes & $14(34.1)$ & $27(65.9)$ & $12.2(1.6-88.9)$ & $<0.001^{*}$ \\
\hline No & $1(2.8)$ & $35(97.2)$ & Reference & \\
\hline \multicolumn{5}{|c|}{ Visible plaque } \\
\hline Yes & $26(76.5)$ & $8(23.5)$ & $4.1(2.1-7.8)$ & $<0.001^{*}$ \\
\hline No & 8 (18.6) & $35(81.4)$ & Reference & \\
\hline
\end{tabular}

*Statistically significant difference (chi-squared test or fisher exact test). PR: Prevalence ratio, Cl: Confidence interval, GB: Gingival bleeding

\begin{tabular}{|c|c|c|c|c|c|c|c|}
\hline \multicolumn{2}{|c|}{ Variables } & \multicolumn{3}{|c|}{$\begin{array}{l}\text { Nonstandardized } \\
\text { coefficients }\end{array}$} & \multirow{2}{*}{$\begin{array}{c}\text { Standardized } \\
\text { coefficient } \\
\text { Beta } \\
\end{array}$} & \multirow[t]{2}{*}{$t$} & \multirow[t]{2}{*}{$P$} \\
\hline Dependent & Independent & Constant & Beta & SE & & & \\
\hline Caries/child & Caries/mother & 0.506 & 0.233 & 0.037 & 0.568 & 5.299 & $0.000^{*}$ \\
\hline Filled/child & Filled/mother & 0.403 & 0.333 & 0.065 & 0.443 & 4.279 & $0.000^{*}$ \\
\hline IVP/child & IVP/mother & 0.030 & 0.652 & 0.061 & 0.657 & 7.556 & 0.000 * \\
\hline IGB/child & IGB/mother & 0.028 & 0.314 & 0.084 & 0.395 & 3.726 & $0.000^{*}$ \\
\hline
\end{tabular}


The results found in this research are in accordance with studies that claim that the better the maternal level of education, the lower the occurrence of caries in children. ${ }^{[13-15]}$

Epidemiological studies carried out in the past 20 years point to an inequality among different social classes in the experience of dental caries. ${ }^{[16,17]}$ This study found no significant association between household income and the presence of ECC. This difference can be explained by the fact that, in this study, the average household income was relatively high, varying between 1 and 3 minimum wages. In addition to this, the mothers' education level must be taken into consideration.

In this study, most mothers reported that their children breastfeed to sleep and/or nurse during the night [Table 1]. The American Academy of Pediatric Dentistry (AAPD) ${ }^{[18]}$ considers breastfeeding on demand after tooth eruption to be a risk factor for the development of the caries disease, which is in agreement with other studies. ${ }^{[19-21]}$ However, it should be considered that the relationship between prolonged breast-feeding and the emergence of caries is complex and may be confused by others factors such age, sucrose consumption between main meals, and quality of oral hygiene. ${ }^{[22]}$

In this study, the high frequency of using a bottle at night, as well as the addition of sugar thereto, as reported by the mothers [Table 1], are risk factors for ECC. Regarding children's diet, during the home visits it was found that the consumption of sugary foods, offered by the mothers to their children between meals, is high and indiscriminate. There is a known correlation between family dietary pattern and the experience of ECC. ${ }^{[23,24]}$ The Streptococcus mutans group has a decisive effect on the development of ECC, since they are exposed to a cariogenic diet. ${ }^{[25]}$ Research shows that the precursor microorganism for caries is transmissible; and the vertical mother-child relationship of transmissibility has been emphasized over the years. ${ }^{[25,26]}$ A study conducted in Thailand found $S$. mutans in salivary samples collected from children under the age of 2 months, ${ }^{[26]}$ demonstrating the early vertical transmission of this microorganism. Thus, the dietary pattern associated with the transmissibility of the precursor microorganism must be considered a causal factor of ECC.

The lack of guidance regarding the family's and the baby's oral hygiene was also a predominant factor in this study. The majority of mothers as shown in
Table 2, did not receive information on dental care during pregnancy. In addition to that, they don't know when to start the baby's oral hygiene or when to visit the dentist for the $1^{\text {st }}$ time. When the mothers received some type of information, it was from the pediatric physician. Studies prove the effectiveness of information in the fight against tooth decay, since family knowledge about tooth decay is a protection factor against ECC. ${ }^{[20,24,27,28]}$

Recently published studies prove the effectiveness of early dental care in children under 3 years of age. ${ }^{[19,29]}$ The AAPD recommends that the best time to start dental care is between the ages of 6 and 12 months. ${ }^{[18]}$ In this study, we observed that mothers do not know when to take their children to their first visit to the dentist.

Clinical examination showed that there might be an association between the presence of caries in the mother-child binomial ( $\mathrm{PR}=22.5, \mathrm{CI} 95 \%=3.2-156.6)$. As shown in Table 4, the average number of mothers' decayed teeth is equivalent to their respective children. The same positive correlation between mothers and children was found regarding the indices of GB and visible plaque.

During supervised brushing, it was observed that most mothers did not do it effectively. In addition to inadequate brushing, mothers also used an exaggerated amount of toothpaste, which often was swallowed by the child. This information is important to explain the contradiction between the high frequency of oral hygiene reported by mothers as well as the use of fluoride toothpaste associated with tooth brushing, and the data found during the clinical examination regarding caries, GB and visible plaque.

The findings of this study are in accordance with the literature and highlight the importance of the mother in the baby's health care. Moreover, this fact reinforces the importance of incorporating mothers in preventive oral health practice.

\section{CONCLUSION}

Within the limits of this research, these findings suggest that the maternal caries status was associated with ECC. Most mothers are unaware of early caries disease and its risk factors; and as they are the main transmission agents, it justifies the need for setting up preventive educational programs in oral health in the maternal-infant health units. 


\section{REFERENCES}

1. Fejerskov O, Kidd EAM. Dental caries: The disease and its clinical management. London, Blackwell Munksgaard, 2003.

2. Drury TF, Horowitz AM, Ismail AI, Maertens MP, Rozier RG, Selwitz RH. Diagnosing and reporting early childhood caries for research purposes. A report of a workshop sponsored by the National Institute of Dental and Craniofacial Research, the Health Resources and Services Administration, and the Health Care Financing Administration. J Public Health Dent 1999;59:192-7.

3. Leong PM, Gussy MG, Barrow SY, de Silva-Sanigorski A, Waters E. A systematic review of risk factors during first year of life for early childhood caries. Int J Paediatr Dent 2013;23:235-50.

4. Naidu R, Nunn J, Kelly A. Socio-behavioural factors and early childhood caries: A cross-sectional study of preschool children in central Trinidad. BMC Oral Health 2013;13:30.

5. Pannu P, Gambhir R, Sujlana A. Correlation between the salivary Streptococcus mutans levels and dental caries experience in adult population of Chandigarh, India. Eur J Dent 2013;7:191-5.

6. Kumar S, Kroon J, Lalloo R. A systematic review of the impact of parental socio-economic status and home environment characteristics on children's oral health related quality of life. Health Qual Life Outcomes 2014;12:41.

7. Casamassimo PS, Thikkurissy S, Edelstein BL, Maiorini E. Beyond the $\mathrm{dmft}$ : The human and economic cost of early childhood caries. J Am Dent Assoc 2009;140:650-7.

8. Duijster D, Verrips GH, van Loveren C. The role of family functioning in childhood dental caries. Community Dent Oral Epidemiol 2014;42:193-205.

9. Shearer DM, Thomson WM, Caspi A, Moffitt TE, Broadbent JM, Poulton R. Family history and oral health: Findings from the Dunedin Study. Community Dent Oral Epidemiol 2012;40:105-15.

10. Shearer DM, Thomson WM. Intergenerational continuity in oral health: A review. Community Dent Oral Epidemiol 2010;38:479-86.

11. Warren JJ, Weber-Gasparoni K, Marshall TA, Drake DR, Dehkordi-Vakil F, Kolker JL, et al. Factors associated with dental caries experience in 1-year-old children. J Public Health Dent 2008;68:70-5.

12. Brandão IM, Arcieri RM, Sundefeld ML, Miomaz SA. Early childhood caries: the influence of socio-behavioral variables and health locus of control in a group of children from Araraquara, São Paulo, Brazil. Cad Saúde Publica 2006;22:1247-56.

13. Tanaka K, Miyake Y, Sasaki S, Hirota Y. Socioeconomic status and risk of dental caries in Japanese preschool children: The Osaka Maternal and child health study. J Public Health Dent 2013;73:217-23.

14. Ozer S, Sen Tunc E, Bayrak S, Egilmez T. Evaluation of certain risk factors for early childhood caries in Samsun, Turkey. Eur J Paediatr Dent 2011;12:103-6.

15. Zhou Y, Lin HC, Lo EC, Wong MC. Risk indicators for early childhood caries in 2-year-old children in southern China. Aust Dent J 2011;56:33-9.

16. Hashim R, Williams S, Thomson WM. Severe early childhood caries and behavioural risk indicators among young children in Ajman, United Arab Emirates. Eur Arch Paediatr Dent 2011;12:205-10.
17. Seow WK, Clifford H, Battistutta D, Morawska A, Holcombe T. Case-control study of early childhood caries in Australia. Caries Res 2009;43:25-35.

18. American Academy of Pediatric Dentistry, Reference manual 2003-2004. Pediatr Dent 2003;25:1-150.

19. Mohebbi SZ, Virtanen JI, Vahid-Golpayegani M, Vehkalahti MM. Feeding habits as determinants of early childhood caries in a population where prolonged breastfeeding is the norm. Community Dent Oral Epidemiol 2008;36:363-9.

20. Slabsinskiene E, Milciuviene S, Narbutaite J, Vasiliauskiene I, Andruskeviciene V, Bendoraitiene EA, et al. Severe early childhood caries and behavioral risk factors among 3-year-old children in Lithuania. Medicina (Kaunas) 2010;46:135-41.

21. Folayan MO, Sowole CA, Owotade FJ, Sote E. Impact of infant feeding practices on caries experience of preschool children. J Clin Pediatr Dent 2010;34:297-301.

22. Nunes AM, Alves CM, Borba de Araújo F, Ortiz TM, Ribeiro MR, Silva AA, et al. Association between prolonged breast-feeding and early childhood caries: A hierarchical approach. Community Dent Oral Epidemiol 2012;40:542-9.

23. Feldens CA, Giugliani ER, Vigo Á, Vítolo MR. Early feeding practices and severe early childhood caries in four-year-old children from southern Brazil: A birth cohort study. Caries Res 2010;44:445-52.

24. Zhong ZQ. The relationship between the infant nursing bottle caries and the feeding patterns, oral health behavior and parents' oral health information. Shanghai Kou Qiang Yi Xue 2009;18:588-91.

25. Caufield PW, Cutter GR, Dasanayake AP. Initial acquisition of mutans streptococci by infants: Evidence for a discrete window of infectivity. J Dent Res 1993;72:37-45.

26. Tankkunnasombut S, Youcharoen K, Wisuttisak W, Vichayanrat S, Tiranathanagul S. Early colonization of mutans streptococci in 2- to 36-month-old Thai children. Pediatr Dent 2009;31:47-51.

27. Duijster D, van Loveren C, Dusseldorp E, Verrips GH. Modelling community, family, and individual determinants of childhood dental caries. Eur J Oral Sci 2014;122:125-33.

28. Singh A, Gambhir RS, Singh S, Kapoor V, Singh J. Oral health: How much do you know? - A study on knowledge, attitude and practices of patients visiting a North Indian dental school. Eur J Dent 2014;8:63-7.

29. Campos JA, Lima NA. Early childhood caries etiopathogenesis: Maternal knowledge ascribed to doctor or dentist instruction. Rev Odontol UNESP 2007;36:217-22.

\begin{tabular}{|l|l|}
\hline \multicolumn{2}{|c|}{ Access this article online } \\
\hline Quick Response Code: & Website: \\
& www.eurjdent.com \\
\cline { 2 - 4 } & Source of Support: Nil. \\
\hline
\end{tabular}

